• 研究报告・

\title{
云南恆族传统文化对蔬菜种质多样性的影响
}

\author{
邵桦 薛达元 ${ }^{*}$ \\ (中央民族大学生命与环境科学学院, 北京 100081)
}

\begin{abstract}
摘要: 本文在实地调研的基础上, 对云南沧源县与西盟县传统蔬菜种质资源与佤族传统文化之间的关系进行了研 究。结果表明: (1)低族常用蔬菜110种, 隶属40科85属, 其中栽培蔬菜60种, 野生蔬菜50种。栽培蔬菜包括53个传 统品种, 36个引进品种。(2) 1985-2015年来低族种植蔬菜种类增多, 但传统蔬菜种类呈下降趋势。(3)低族传统文 化从食用蔬菜部位多样性、饮食习惯、祖先情怀、“药食同源”及传统留种换种方式等方面对蔬菜种质资源的保存 与传承利用具有重要影响。本文还对传统文化与传统蔬菜种质资源的丧失及影响因素进行了分析, 提出应加强民 族传统文化保护以促进当地传统蔬菜种质资源的保护与可持续利用。
\end{abstract}

关键词: 传统文化; 蔬菜种质资源; 佤族; 云南

\section{Influence of traditional Wa culture on vegetable germplasm diversity in Yunnan Province}

\author{
Hua Shao, Dayuan Xue* \\ College of Life and Environmental Sciences, Minzu University of China, Beijing 100081
}

\begin{abstract}
Based on field studies, the relationship between traditional vegetable germplasm resources and the traditional culture of the Wa ethnic group in Cangyuan County and Ximeng County of Yunnan Province was explored. Results showed that there were 110 species of vegetable resources used by Wa people frequently, belonging to 40 families and 85 genera, containing 60 species of cultivated vegetables and 50 species of wild vegetables. Cultivated vegetables were divided into 53 traditional cultivars and 36 introduced cultivars. During 1985-2015, home-grown vegetable cultivars used by the Wa people increased, but the cultivars of traditional vegetables decreased. The traditional culture of the Wa people, characterized by diversified utilization of vegetables' edible parts, eating habits, respect to ancestors, the "homology of medicine and food" and traditional seed reserve and exchange methods, played an important role in the conservation and utilization of vegetable germplasm resources. This paper also analyzed the possible loss and influence factors of traditional vegetable germplasm resources, and suggestions were proposed for strengthening the protection of the traditional ethnic culture, and subsequently, promotion of the protection and sustainable utilization of local traditional vegetable germplasm resources.
\end{abstract}

Key words: traditional culture; vegetable germplasm resources; Wa people; Yunnan Province

生物多样性的保护与民族文化多样性保护相 辅相成(许再富和刘宏茂, 1995; 薛达元和郭胨, 2009a; 裴盛基，2011; 许再富，2015)，传统种质资 源和相关的传统知识迅速消失，使传统文化与生物 多样性保护及可持续利用的关系成为生物多样性 领域的热点(薛达元和郭胨, 2009b; 薛达元等,
2012)。民族传统文化对当地农作物品种资源的保护 与利用具有重要影响(哈斯巴根等, 2011; Tamang et al, 2014; Pieroni et al, 2015; 王艳杰等, 2015)。我国 许多少数民族地区因其独特的地理环境、丰富的生 物多样性而造就了文化的多样性(龙春林等, 1999), 培育、驯化并保存了大量优良蔬菜种质资源(王洁如 
和龙春林, 1995; 刘怡涛和龙春林, 2001; 李卫芬等, 2010, 2016; 郑希龙等, 2013)。

云南沧源仾族自治县与西盟俪族自治县是恆 族人口最为聚集的地区, 这里位于西南边陲, 地理 位置偏僻, 交通不便, 与外界交流很少, 导致该地 区经济比较落后, 仍然保持了传统生活方式(罗之 基, 1995; 邹欢, 2009), 特别是长期以来利用了许多 野生蔬菜资源(刘川宇等, 2012)。但是, 近年来随着 对外开放和外来文化的渗入, 传统利用的蔬菜种质 资源呈下降趋势。为了保护传统蔬菜种质资源及其 相关的传统知识, 本研究选择在云南沧源和西盟两 个仾族自治县, 通过对被选乡村的实际考察和问卷 调查, 旨在查明低族保存和利用传统蔬菜种质资源 的现状, 研究低族民族文化对当地利用和保存传统 蔬菜种质资源的影响, 并通过对关键影响因素的分 析, 探讨保护仾族传统文化进而保护蔬菜遗传多样 性的途径。

\section{1 低族传统蔬菜种质资源利用现状}

根据种植蔬菜情况与社会文化因素的差异, 选 取了 6 个仾族村寨, 调查了 60 个农户。共调查仾族常 用蔬菜 110 个种, 隶属于 40 科 85 属。其中栽培蔬菜 17 科41属60种, 野生蔬菜31科 45 属 50 种(表1), 占蔬菜 总种数的 $45.45 \%$ 。栽培蔬菜包含 53 个俪族历史上选 育栽培的传统蔬菜品种(表2)和36个新引进的蔬菜 品种, 反映出恆族地区不仅遗传多样性丰富, 而且 基本上维持了传统的生产和生活方式。

问卷和访谈结果表明，从1985-2015年的30年 中恆族家庭平均种植蔬菜种类数量呈现增长趋势, 尤其2010-2015年增长速度加快, 主要是引进栽培 的蔬菜种类呈增长趋势。与其相对的是, 恆族社区 栽培的传统蔬菜种类呈现下降趋势, 2010-2015年 下降趋势加快(图1)。

\section{2 民族传统文化对蔬菜种质资源的影响}

低族人民在驯化和栽培蔬菜植物的历史过程 中, 创造并积累了大量的传统知识, 这不仅与㑑族 地区自然资源分布有关，也与㑑族本民族的生产生 活方式有关。当地人民在培育栽培农作物的过程中， 发展了丰富的食品文化, 而这些食品文化又促进了 新的农作物品种的驯化。传统文化对蔬菜种质资源 的影响主要体现在以下几方面。

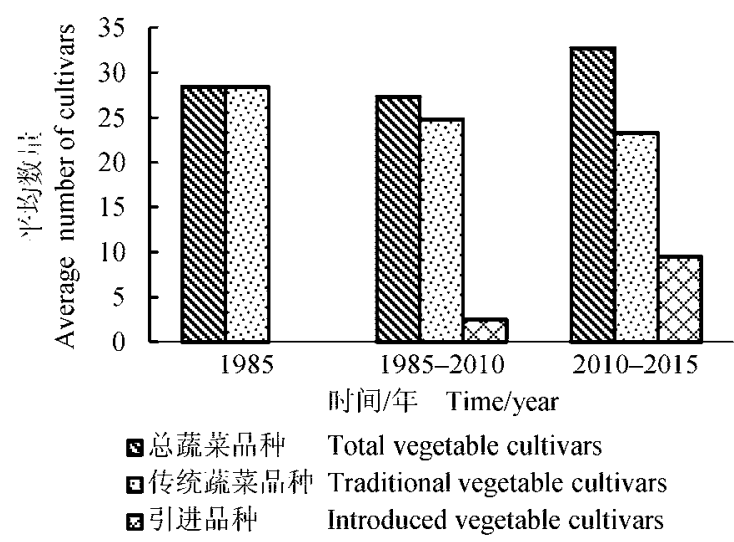

图1 1985-2015年恆族村寨平均家庭栽培蔬菜品种数量 变化

Fig. 1 Variation in average home-grown vegetable cultivars in Wa villages during 1985-2015

\section{1 食用蔬菜部位多样}

仾族人民食用蔬菜部位的多样性体现了他们 对植物资源的可持续利用方式。根据调查，低族对 传统蔬菜植物的利用部位大致分为根、茎、嫩叶/ 芽、果实、花/花序、全草、种子等7类。其中利用 蔬菜最多的部位是可以繁殖更新的嫩茎叶, 占 $59.9 \%$, 例如宝塔菜、臭菜、革命菜等野生蔬菜，这 种采摘方式可促进蔬菜植体的自然更新和可持续 利用; 利用果实部位的蔬菜次之, 占 $20.86 \%$, 多为 瓜类、茄果类，如刺茄、杧果、大树番茄等，对这 类蔬菜，当地非常注重对优良果实的选种和留种; 低族具有食花文化,食用花/花序部位的蔬菜占 $10.7 \%$, 野生植物如白花羊蹄甲、芭蕉花、火烧花等 的花可作为蔬菜食用，但多间隔采摘。

\section{2 传统饮食习惯}

㑑族人的传统饮食习惯促进了食用蔬菜种类 的多样性。当地人喜欢食用瓜类、野生蔬菜类、茄 果类、葱蒜类、叶菜类、薯蓣类等蔬菜，这不仅与本 地生物资源有关，也与低族本民族的饮食习俗有关 (苏艳等, 2012)。西盟地区的佤族都喜欢用新鲜蔬菜 和盐、米、辣椒、肉类一锅煮成较稠烂饭, 味道极为 鲜美。有的地区主食以干饭为主, 副食主要是以青菜 类、瓜类、酸竹笋、盐、辣椒、蒜和鲜肉謷汤菜就 饭, 这也是低族平时最讲究的一种饭食。因许多人喜 欢咸辣口味, 种植调料类的蔬菜种类就较多; 此外, 也有人喜欢食用炒、腌渍、煮的食用方式。这些传 统食用方式客观上要求种植更多蔬菜种类。 
表1 云南仾族利用的野生蔬菜资源

Table 1 List of the wild vegetable resources used by Wa people

\begin{tabular}{|c|c|c|c|c|}
\hline 种 Species & 地方名称 Local name & 科 Family & 食用部位 Edible parts & 食用方法 Edible methods \\
\hline \multirow[t]{2}{*}{ 羽叶金合欢 Acacia pennata } & 臭菜 Plume acacia & 豆科 & 嫩茎叶、嫩梢 & 凉拌、与鸡蛋炒食 \\
\hline & & Leguminosae & Tender leaf, stem and shoots & Salad, fry with eggs \\
\hline \multirow[t]{2}{*}{ 刺五加 Acanthopanax trifoliatus } & 刺五加 & 五加科 & 嫩茎叶 Tender leaf and stem & 炒食 Fry \\
\hline & $\begin{array}{l}\text { Trifoliate acanthopanax } \\
\text { 刺老包 }\end{array}$ & $\begin{array}{l}\text { Araliaceae } \\
\text { 五加科 }\end{array}$ & & \\
\hline 淴木 Aralia chinensis & $\begin{array}{l}\text { 籼龙尼 } \\
\text { Chinese aralia }\end{array}$ & $\begin{array}{l}\text { 五乃ロ科 } \\
\text { Araliaceae }\end{array}$ & 婌牙、叶 I ender leat and bud & 少良、你抨 Fry, salad \\
\hline \multirow[t]{2}{*}{ 落葵 Basella alba } & 木耳菜 & 落葵科 & 嫩茎叶 Tender leaf and stem & 煮食、炒食、做汤 Boil, fry, soup \\
\hline & White vinespinach & Basellaceae & & \\
\hline 白花羊蹄甲 Bauhinia acuminata & $\begin{array}{l}\text { 大白花 } \\
\text { Snowy bauhinia }\end{array}$ & $\begin{array}{l}\text { 豆科 } \\
\text { Leguminosae }\end{array}$ & 花 Flower & 开水漂洗后煮食、炒食 Boil, fry \\
\hline 密蒙花 Buddleja officinalis & 染饭花 ～～～～～～～～～ & 马钱科 & 花 Flower & 黄色食品染料 \\
\hline 番木瓜 Carica papaya & $\begin{array}{l}\text { Pale butterflybush } \\
\text { 木瓜 } \\
\text { Papaya }\end{array}$ & $\begin{array}{l}\text { Loganiaceae } \\
\text { 番木瓜科 } \\
\text { Caricaceae }\end{array}$ & $\begin{array}{l}\text { 果实、嫩茎叶、花序 } \\
\text { Fruit, tender leaf, stem, inflorescence }\end{array}$ & $\begin{array}{l}\text { A yellow dye for food dyeing } \\
\text { 生食凉拌 Salad }\end{array}$ \\
\hline 积雪草 Centella asiatica & 马蹄金 & 企形科 & 全草 Whole plant & 生食、炒食或做汤 \\
\hline 水蕨 Ceratopteris thalictroides & $\begin{array}{l}\text { Asiatica pennywort } \\
\text { 水顸 } \\
\text { Floating fern }\end{array}$ & $\begin{array}{l}\text { Umbelliferae } \\
\text { 水蕨科 } \\
\text { Parkeriaceae }\end{array}$ & 嫩茎叶 Tender leaf and stem & $\begin{array}{l}\text { Raw eating, fry, soup } \\
\text { 炒食 Fry }\end{array}$ \\
\hline \multirow{2}{*}{$\begin{array}{l}\text { 野茼蒿 Crassocephalum } \\
\text { crepidioides } \\
\text { 树头菜 Crateva unilocularis }\end{array}$} & 革命菜/民国菜 & 菊科 & 嫩茎叶、幼苗 & 炒食、煮食、凉拌 \\
\hline & $\begin{array}{l}\text { Redflower ragleaf } \\
\text { 鸡爪菜 }\end{array}$ & $\begin{array}{l}\text { Compositae } \\
\text { 山柑科 }\end{array}$ & $\begin{array}{l}\text { Tender leaf, stem and seedling } \\
\text { 嫩叶和茎梢 Tender leaf and shoots }\end{array}$ & $\begin{array}{l}\text { Fry, boil, salad } \\
\text { 炒食、凉拌 Fry, salad }\end{array}$ \\
\hline 柠檬草 Cymbopogon citratus & $\begin{array}{l}\text { Crateva } \\
\text { 香茅草 }\end{array}$ & $\begin{array}{l}\text { Capparaceae } \\
\text { 禾本科 }\end{array}$ & 嫩茎叶 Tender leaf and stem & 香料 Spice \\
\hline 树番茄 Cyphomandra betacea & $\begin{array}{l}\text { Lemongrass } \\
\text { 树番茄 } \\
\text { Treetomao }\end{array}$ & $\begin{array}{l}\text { Gramineae } \\
\text { 茄科 } \\
\text { Solanaceae }\end{array}$ & 果实 Fruit & $\begin{array}{l}\text { 生食、凉拌、炒食 } \\
\text { Eat raw, salad, fry }\end{array}$ \\
\hline \multirow{3}{*}{$\begin{array}{l}\text { 版纳甜龙竹 Dendrocalamus } \\
\text { hamiltonii } \\
\text { 水香薷 Elsholtzia kachinensis }\end{array}$} & 甜笋 & 禾本科 & 初生、嫩肥、短壮的芽或鞭 & 凉拌、炒食、煮食 \\
\hline & Hamilton dendrocalamus & Gramineae & Tender shoots & Salad, fry, boil \\
\hline & 水香菜 & 唇形科 & 嫩茎叶 Tender leaf and stem & 生食或做汤 Eat raw, soup \\
\hline 枇杷 Eriobotrya japonica & $\begin{array}{l}\text { Kachin elsholtzia } \\
\text { 枇杷 } \\
\text { Loguat }\end{array}$ & $\begin{array}{l}\text { Labiatae } \\
\text { 葍薇科 } \\
\text { Rosaceae }\end{array}$ & 叶 Leaf & 切丝生用 Shred and raw eating \\
\hline \multirow[t]{2}{*}{ 芝麻菜 Eruca sativa } & 芝麻菜 & 十字花科 & 嫩茎叶 Tender leaf and stem & 炒食 Fry \\
\hline & Roquette & Cruciferae & & \\
\hline \multirow[t]{2}{*}{ 刺芹 Eryngium foetidum } & 阿㑑芫荽 & 伞形科 & 全株或嫩茎叶 & 佐料 Seasoning \\
\hline & Foecid eryngo & $\begin{array}{l}\text { Umbelliferae } \\
\text { 茎香利 }\end{array}$ & Whole plant or tender leaf and stem & \\
\hline 三桠苦 Evodia lepta & $\begin{array}{l}\text { 小黄散 } \\
\text { Thin evodia }\end{array}$ & $\begin{array}{l}\text { 芸香科 } \\
\text { Rutaceae }\end{array}$ & 叶 Leaf & 烘干后做汤 Drying for soup \\
\hline 矮萱草 Hemerocallis nana & $\begin{array}{l}\text { 黄花菜 } \\
\text { Little daylily }\end{array}$ & $\begin{array}{l}\text { 百合科 } \\
\text { Liliaceae }\end{array}$ & 花 Flower & 炒食、煮食 Fry, boil \\
\hline \multirow[t]{2}{*}{ 菚菜 Houttuynia cordata } & 折耳根/鱼腥草 & 三白草科 & 根茎、嫩茎叶 & 凉拌、炒食、腌渍、煮汤 \\
\hline & $\begin{array}{l}\text { Heartleaf houttuynia } \\
\text { 鸡儿菜 }\end{array}$ & $\begin{array}{l}\text { Saururaceae } \\
\text { 菊科 }\end{array}$ & $\begin{array}{l}\text { Root, stem and tender shoots } \\
\text { 嫩叶、幼苗 }\end{array}$ & $\begin{array}{l}\text { Salad, fry, pickle, soup } \\
\text { 炒食、凉拌 Fry, salad }\end{array}$ \\
\hline 马兰 Kalimeris indica & India kalimeris & Compositae & Tender leaf and seedling & \\
\hline \multirow[t]{2}{*}{ 山鸡椒 Litsea cubeba } & 木姜子 & 樟科 & 嫩茎叶、果实 & 佐料 Seasoning \\
\hline & Fragrant litse & Lauraceae & Tender leaf, stem an & \\
\hline \multirow[t]{2}{*}{ 杧果 Mangifera indica } & 杧果 & 漆树科 & 果实 Fruit & 生食、腌渍 \\
\hline & Mango & Anacardiaceae & & Raw eating, pickle \\
\hline 火烧花 Mayodendron igneum & 炮仗花 & 紫蒇科 & 鲜花 Fresh flower & 开水焯后炒食 \\
\hline 树头芭蕉 Musa wilsonii & $\begin{array}{l}\text { Brightred mayodendron } \\
\text { 芭蕉 }\end{array}$ & $\begin{array}{l}\text { Bignoniaceae } \\
\text { 芭蕉科 }\end{array}$ & 假茎和嫩叶、花序 & $\begin{array}{l}\text { Fry after boiling } \\
\text { 炒食 Fry }\end{array}$ \\
\hline & Wilson banana & Musaceae & Tender leaf, stem and inflorescence & \\
\hline 水芹 Oenanthe javanica & $\begin{array}{l}\text { 水耎采/野耎采 } \\
\text { Bengal water dropwort }\end{array}$ & $\begin{array}{l}\text { 伞形枓 } \\
\text { Umbelliferae }\end{array}$ & $\begin{array}{l}\text { 嫩茎、叶枘、花茎 } \\
\text { Tender leaf, stem, petiole and flower }\end{array}$ & 食、凉拌 Fry, salad \\
\hline 木蝴蝶 Oroxylum indium & 海船 & 紫葳科 & 花、幼嫩的果、嫩叶 & 嫩叶焯水春食、嫩果炒食或腌渍 \\
\hline 海菜花 Ottelia acuminata & $\begin{array}{l}\text { India trumpetflower } \\
\text { 海白菜 }\end{array}$ & $\begin{array}{l}\text { Bignoniaceae } \\
\text { 水鳖科 }\end{array}$ & $\begin{array}{l}\text { Flower, tender leaf and fruit } \\
\text { 花、嫩叶 Flower and tender leaf }\end{array}$ & $\begin{array}{l}\text { Pound leaf, fry or pickle fruit } \\
\text { 炒食 Fry }\end{array}$ \\
\hline & Yunnan ottelia & Hydrocharitaceae & & \\
\hline 连芯藤 Parabaena sagittata & 犁板菜 & 防己科 & 嫩茎叶 Tender leaf and stem & 炒食或做汤 Fry, soup \\
\hline 黄花胡椒 Piper flaviflorum & $\begin{array}{l}\text { Sagittate parabaena } \\
\text { 野芦子 }\end{array}$ & $\begin{array}{l}\text { Menispermaceae } \\
\text { 胡椒科 }\end{array}$ & 老茎 Old stem & 佐料 $\mathrm{Se}$ \\
\hline S & Flaviflorum pepper & Piperaceae & 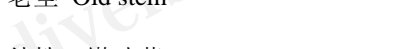 & VLT'T SE \\
\hline 车前 Plantago asiatica & 车前草 & 车前科 & 幼株、嫩叶芽 & 凉拌、炒食、煮食 \\
\hline & Asiatic plantain & Plantaginaceae & Tender leaf, bud, whole plant & Salad, fry, boil \\
\hline 苦竹 Pleioblastus amarus & 苦笋 & 禾本科 & 初生、嫩肥、短壮的芽或鞭 & 凉拌、炒食、腌渍 \\
\hline & Amarus pleioblastus & Gramineae & Tender shoots & Salad, fry, pickle \\
\hline
\end{tabular}


表1 (续) Table 1 (continuous)

\begin{tabular}{|c|c|c|c|c|}
\hline 种 Species & 地方名称 Local name & 科 Family & 食用部位 Edible parts & 食用方法 Edible methods \\
\hline $\begin{array}{l}\text { 鸡蛋花 Plumeria rubra Acutifo- } \\
\text { lia } \\
\text { 香蓼 Polygonum viscosum }\end{array}$ & $\begin{array}{l}\text { 马鹿角 } \\
\text { Mexican frangipani } \\
\text { 香蓼 } \\
\text { Viscidhairy knotweed }\end{array}$ & $\begin{array}{l}\text { 夹竹桃科 } \\
\text { Apocynaceae } \\
\text { 蓼科 } \\
\text { Polygonaceae }\end{array}$ & $\begin{array}{l}\text { 花、茎 Flower and stem } \\
\text { 嫩茎叶 Tender leaf and stem }\end{array}$ & $\begin{array}{l}\text { 花瓣炸食、茎枝切片与猪脚煮食 } \\
\text { Fry petals, boil stem } \\
\text { 佐料 Seasoning }\end{array}$ \\
\hline 马齿苋 Portulaca oleracea & $\begin{array}{l}\text { 马齿苋 } \\
\text { Purslane }\end{array}$ & $\begin{array}{l}\text { 马齿苋科 } \\
\text { Portulacaceae }\end{array}$ & 嫩茎叶 Tender leaf and stem & $\begin{array}{l}\text { 沸水焯水后凉拌、炒食 } \\
\text { Salad, fry }\end{array}$ \\
\hline 欧洲蕨 Pteridium aquilinum & $\begin{array}{l}\text { 龙须菜 } \\
\text { Bracken fern }\end{array}$ & $\begin{array}{l}\text { 蕨科 } \\
\text { Pteridiaceae }\end{array}$ & 嫩芽叶 Tender leaf and bud & $\begin{array}{l}\text { 沸水焯水后凉拌、炒食 } \\
\text { Salad, fry }\end{array}$ \\
\hline 盐肤木 Rhus chinensis & $\begin{array}{l}\text { 盐肤木 } \\
\text { Chinese sumac }\end{array}$ & $\begin{array}{l}\text { 漆树科 } \\
\text { Anacardiaceae }\end{array}$ & $\begin{array}{l}\text { 果实及嫩茎叶 } \\
\text { Fruit, tender leaf and stem }\end{array}$ & $\begin{array}{l}\text { 果实春后泡水、凉拌菜的酸源 } \\
\text { An acid source for salad }\end{array}$ \\
\hline $\begin{array}{l}\text { 千年不烂心 Solanum catha- } \\
\text { yanum }\end{array}$ & $\begin{array}{l}\text { 苦子 } \\
\text { Chinese nightshade }\end{array}$ & $\begin{array}{l}\text { 茄科 } \\
\text { Solanaceae }\end{array}$ & 果实 Fruit & 炒食 Fry \\
\hline 野茄 Solanum coagulans & $\begin{array}{l}\text { 苦茄 } \\
\text { Wild nightshade }\end{array}$ & $\begin{array}{l}\text { 茄科 } \\
\text { Solanaceae }\end{array}$ & 果实 Fruit & 炒食 Fry \\
\hline 刺天茄 Solanum indicum & $\begin{array}{l}\text { 苦果 } \\
\text { Indian nightshade }\end{array}$ & $\begin{array}{l}\text { 茄科 } \\
\text { Solanaceae }\end{array}$ & 果实 Fruit & 炒食 Fry \\
\hline 龙葵 Solanum nigrum & $\begin{array}{l}\text { 天茄子 } \\
\text { Dwarf nightshade }\end{array}$ & $\begin{array}{l}\text { 茄科 } \\
\text { Solanaceae }\end{array}$ & 嫩叶 Tender leaf & 炒食 Fry \\
\hline $\begin{array}{l}\text { 少花龙葵 Solanum photeino- } \\
\text { carpum } \\
\text { 水茄 Solanum torvum }\end{array}$ & $\begin{array}{l}\text { 苦凉菜 } \\
\text { Violet nightshade } \\
\text { 刺茄 }\end{array}$ & $\begin{array}{l}\text { 茄科 } \\
\text { Solanaceae } \\
\text { 茄科 }\end{array}$ & $\begin{array}{l}\text { 幼苗、嫩茎叶 } \\
\text { Tender bud, leaf and stem } \\
\text { 嫩果实 Tender fruit }\end{array}$ & $\begin{array}{l}\text { 开水漂淴后凉拌、炒食、做汤 } \\
\text { Salad, fry, soup } \\
\text { 炒食、油煎 Fry and oil fry }\end{array}$ \\
\hline 苦芭菜 Sonchus oleraceus & $\begin{array}{l}\text { Water nightshade } \\
\text { 苦苦菜 } \\
\text { Common sowthistle }\end{array}$ & $\begin{array}{l}\text { Solanaceae } \\
\text { 菊科 } \\
\text { Compositae }\end{array}$ & 嫩茎叶 Tender leaf and stem & 炒食、做汤 Fry, soup \\
\hline 甘露子 Stachys sieboldii & $\begin{array}{l}\text { 宝塔菜 } \\
\text { Chinese artichoke }\end{array}$ & $\begin{array}{l}\text { 唇形科 } \\
\text { Labiatae }\end{array}$ & 嫩茎叶 Tender leaf and stem & 炒食 Fry \\
\hline 蒲公英 Taraxacum mongolicum & $\begin{array}{l}\text { 蒲公英 } \\
\text { Mongolian dandelion }\end{array}$ & $\begin{array}{l}\text { 菊科 } \\
\text { Compositae }\end{array}$ & 叶、根 Leaf and root & $\begin{array}{l}\text { 凉拌、炒食、做汤 } \\
\text { Salad, fry, soup }\end{array}$ \\
\hline 苦果 Trevesia palmata & $\begin{array}{l}\text { 刺通草 } \\
\text { Himalayan trevesia }\end{array}$ & $\begin{array}{l}\text { 五加科 } \\
\text { Araliaceae }\end{array}$ & 嫩果实 Fruit & $\begin{array}{l}\text { 嫩果水煮后捣烂食用 } \\
\text { Boiled and pounded }\end{array}$ \\
\hline 马鞭草 Verbena officinalis & $\begin{array}{l}\text { 龙芽草 } \\
\text { European verbena }\end{array}$ & $\begin{array}{l}\text { 马鞭草科 } \\
\text { Verbenaceae }\end{array}$ & 嫩茎叶 Tender leaf and stem & $\begin{array}{l}\text { 炒食、煮食 } \\
\text { Fry, boil }\end{array}$ \\
\hline 菰 Zizania latifolia & $\begin{array}{l}\text { 荠白 } \\
\text { Fewflower wildrice }\end{array}$ & $\begin{array}{l}\text { 禾本科 } \\
\text { Gramineae }\end{array}$ & 肉质茎 Succulent stem & 炒食或凉拌 Fry, salad \\
\hline
\end{tabular}

一些蔬菜属于佤族传统饮食中必不可少的种 类。“鸡肉稀饭”是低族迎宾待客的传统美味佳有, 刺芫荽又称阿仾芫荽, 在低族地区资源丰富, 分布 广泛, 由于其味道清爽, 嫩叶香, 营养价值高, 成 为仾族人制作鸡肉稀饭或传统菜肴的必备蔬菜。仾 族人将滴水芋的茎秆撕去外皮后者汤, 或者与小米 辣、刺芫荌、姜蒜等春食, 这也是低族稀饭配菜的 必备佐料。另外, 臭菜、树头菜、刺五加等也是俪 族制作特有风味菜肴的常用蔬菜。

低族“无辣不欢”的习俗使该地区保存的辣椒的 品种多样, 小米辣有白皮小米辣、老鼠屎辣椒等多 个特异特优品种, 栽培变种涮涮辣, 有“辣中之王” 的称号, 辣口但不伤肠胃, 因其只需将果剖开放汤 里涮几下, 整锅汤即有辣味而得名, 深受仾族人喜 爱。

仾族与傣族、哈尼族相似, 也喜食蘸水(由多种 调味料调制而成的酱汁, 用来蘸菜)。用做蘸水的佐 料多样, 各个家庭根据蔬菜不同而备有多样的调味
搭配, 如香蓼、八角、花椒、荆芥等因具有特殊芳 香, 是仾族制作传统食品的重要调料种类。

\section{3 祖先情怀与口感习惯}

仾族是祖先崇拜意识相当浓厚的民族。传统种 植的种类是祖祖辈辈成功选育并传承下来的宝贵 财富, 即使产量不高, 佤族人也不愿舍弃。因而那 些口感好或品质好的蔬菜能够祖辈传承, 持续留 种, 如紫青菜、圆秆青菜、他朗辣子、红踠豆、老 缅南瓜、老缅冬瓜、永广大蒜等传统蔬菜种类已经 种植近 100 年。唒族有过年食用一碗宽邦青菜的风 俗, 以保佑来年全家平安(李卫芬等, 2010)。另外, 调查还发现, 40 岁以上的当地人对传统栽培蔬菜感 情较深, 习惯于传统蔬菜的口感, 表示会继续种植 传统品种。

\section{4 “药食同源”养生理念}

低族的传统饮食文化与科学的养生理念相当 一致，许多日常食用的蔬菜也是民间常用的植物药 材 (龙鳞, 2005)。例如, 刺五加作为常用药材在俪族 
表2 云南恆族传统栽培蔬菜种质资源

Table 2 List of the germplasm resources of traditionally cultivated vegetables used by Wa people

\begin{tabular}{|c|c|c|c|}
\hline 种名 & 地方品种名 & 种名 & 地方品种名 \\
\hline Species & Local cultivar names & Species & Local cultivar names \\
\hline 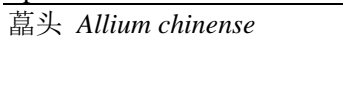 & 蕌头 Rokkyo & 黄瓜 Cucumis sativus & $\begin{array}{l}\text { 地黄瓜、爬架黄瓜、老鼠黄瓜 } \\
\text { Ground cucumber, shelf cucum- } \\
\text { ber, mouse-like cucumber }\end{array}$ \\
\hline 茎菜 Allium hookeri & 荣菜 Hooker onion & 南瓜 Cucurbita moschata & $\begin{array}{l}\text { 本地小南瓜、金瓜、老缅南瓜 } \\
\text { Local small pumpkin, goold pump- } \\
\text { kin, Laos-Burma pumpkin }\end{array}$ \\
\hline 赫 Allium sativum & $\begin{array}{l}\text { 白皮赫、永广大赫、紫皮赫 } \\
\text { White garlic, Yongguang garlic, violet } \\
\text { garlic }\end{array}$ & 薯蓣 Dioscorea batatas & $\begin{array}{l}\text { 山药、细山药、紫山药 } \\
\text { Chinese yam, thin Chinese yam, } \\
\text { purple Chinese yam }\end{array}$ \\
\hline $\begin{array}{l}\text { 细香䓤 Allium schoenopra- } \\
\text { sum }\end{array}$ & 小香葱 Small chive & 八角 Illicium verum & 八角 Anise \\
\hline 非 Allivm tuberosum & 细叶非菜 Spire leek & 丝瓜 Luffa cylindrical & 本地丝瓜 Local towel gourd \\
\hline 苋 Amaranthus tricolor & 薏米菜 Yimi edible amaranth & 番茄 Lycopersicon esculentum & $\begin{array}{l}\text { 细番茄、小番茄 } \\
\text { Thin tomato, small tomato }\end{array}$ \\
\hline $\begin{array}{l}\text { 花蘑芋 Amorphophallus } \\
\text { konjac }\end{array}$ & 魔芋 Konjak & 薄荷 Mentha haplocalyx & 薄荷 Mint \\
\hline 冬瓜 Benincasa hispida & 老缅冬瓜 Laos-Burma wax gourd & 苦瓜 Momordica charantia & 预阿苦瓜 Menge bitter gourd \\
\hline $\begin{array}{l}\text { 节瓜 Benincasa hispida var. } \\
\text { chiehqua }\end{array}$ & 小冬瓜 Small wax gourd & 荆芥 Nepeta cataria & 金戒子 Tenuifolia \\
\hline 芥菜 Brassica juncea & $\begin{array}{l}\text { 大青菜、恆族青菜、紫青菜 } \\
\text { Chinese cabbage, Wa cabbage, violet } \\
\text { cabbage }\end{array}$ & 紫苏 Perilla frutescens & $\begin{array}{l}\text { 白苏子、黑苏子 } \\
\text { White perilla, black perilla }\end{array}$ \\
\hline 蕉芋 Canna edulis & 蕉芋 Banana-like taro & 踠豆 Pisum sativum & 踠豆 Pea \\
\hline $\begin{array}{l}\text { 朝天椒 Capsicum annuum } \\
\text { var. conoides }\end{array}$ & $\begin{array}{l}\text { 朝天辣、小寨辣 } \\
\text { Upturned pepper, Xiaozhai pepper }\end{array}$ & 佛手瓜 Sechium edule & 佛手瓜 Chocho \\
\hline $\begin{array}{l}\text { 簇生椒 Capsicum annuum } \\
\text { var. fasciculatum }\end{array}$ & 他朗辣子 Talang pepper & 茄子 Solanum melongena & $\begin{array}{l}\text { 本地白茄、本地紫茄 Local white } \\
\text { eggplant, local voilet eggplant }\end{array}$ \\
\hline 小米辣 Capsicum frutescens & $\begin{array}{l}\text { 白皮小米辣、小米辣、老鼠屎辣、涮涮 } \\
\text { 辣 White pepper, Xiaomi pepper, mouse } \\
\text { dung-like pepper, Shuanshuan pepper }\end{array}$ & 香椿 Toona sinensis & 香椿 Chinese toon \\
\hline & $\begin{array}{l}\text { 班帅芋头、那卡大麻芋、紫芋 } \\
\text { Banshuai taro, Naka big taro, violet taro }\end{array}$ & 豇豆 Vigna unguiculata & 本地豆角 Local cowpea \\
\hline 大野芋 Coloca & 滴水芋 Dishui taro & 花椒 Zanthoxylun & 花椒 Pepper \\
\hline 芫荽 Coriandrum sativum & 细叶芫荽 Spire Chinese parsley & 姜 Zingiber officinale & 黄姜 Yellow ginger \\
\hline
\end{tabular}

地区已经应用300多年, 有祛风除湿和止痛的功效, 㑑族人常利用该植物的嫩尖凉拌或者加入撒擞(用 特制配料与肉食凉拌的)中食用, 有开胃提振食欲 的作用。有些佤族群众认为使用一种叫尖芭蕉的茎 秆或者花序泡水喝, 可治疗感冒或小孩惊吓后哭闹 (陈洪明等, 2011)。

\section{5 传统留种与换种方式}

传统留种与换种方式可以促进地方蔬菜种质 资源得到篎选、交流、推广与传承。㑑族地方传统 农作物品种几乎全靠自家选种和留种的方式保存。 当地留种方式既简便又经济, 将种子直接挂在火塘 上方烘干，或者自然风干。根据访谈，79\%的家庭蔬 菜种植完全靠自家留种，也有 $8 \%$ 的家庭通过向邻 居或亲友讨要或以互换的方式获得蔬菜种子。村与 村之间也会发生蔬菜种子的互换, 当地蔬菜种子可
在本地市场售卖。

\section{3 问题与展望}

\section{1 传统文化与传统蔬菜资源逐渐消失}

经济社会快速发展和外来文化的渗透是影响 传统文化传承的重要因素。调查结果表明, 恆族地 区近年经济得到快速发展，农民收入显著提高。由 于进城务工及农村产业结构的调整，以及特色农业 和规模农业发展等因素，农村劳动力显著减少，恆 族地区家庭种植蔬菜的传统习惯也随之改变。他们 不再满足于自给自足的传统农业生产方式, 转而外 出打工或从事其他产业, 导致留种习惯改变, 传统 蔬菜的种植逐渐减少。

语言文化的丢失也使仾族人民的民族认同感 显著降低。40岁以下的低族年青人掌握恆语的水平 
比其年长者差, 长期生活在城镇中的佤族人比生活 在村寨内的仾族人要差。现如今, 虽然多数中老年 人对传统蔬菜仍然存有感情, 但青年人使用传统蔬 菜制作家庭食品的认同感逐渐降低, 甚至多数人已 不能使用本民族语言命名当地蔬菜。与此同时, 使 用本民族语言来描述的相关传统知识也有可能一 同消失。

\section{2 传统文化与传统蔬菜种质资源之间的依存关} 系

传统农作物种质资源的保存与可持续利用是 确保相关民族文化习俗传承的基础, 而民族传统文 化和生活习俗也保护和促进了与该民族人民生活 息息相关的农作物种质资源(陈光等, 2010)。俪族人 民依靠丰富的蔬菜种质资源和自身的聪明才智, 满 足了生产和生活的需求, 同时也创造了保护生物多 样性和可持续利用生物资源的文化。俩族的蔬菜饮 食文化对传统蔬菜资源的保护利用起到了积极的 作用(郑殿升等, 2012)。需要充分理解传统文化与农 作物种质资源保护之间相辅相成的关系。

\section{3 弘扬民族文化, 促进传统蔬菜种质资源的保} 护与可持续利用

低族地区存在大量特异的传统蔬菜种质资源, 由于其重要价值而具有开发利用的潜力。要借助民 族特色饮食文化、特色节庆及特色旅游等, 促进传 统蔬菜种质资源的推广应用。可以充分利用饮食习 俗和传统特色蔬菜资源来发展地方产业, 如发展特 色佐料、特色腌菜、特色菜的品牌产业, 以促进保 护和可持续利用传统蔬菜种质资源, 并促进少数民 族地区和谐生态文明社会的建立。

\section{参考文献}

Chen G, You CL, Hu ZR, Shen D, Li LH, Liu X (2010) Investigation of landrace resources of main crops in Xishuangbanna, Yunnan Province. Journal of Plant Genetic Resources, 11, 335-342. (in Chinese with English abstract) [陈 光, 游承俐, 胡忠荣, 沈镝, 李立会, 刘旭 (2010) 西双 版纳少数民族地区主要作物地方品种调查与分析. 植物 遗传资源学报, 11, 335-342.]

Chen HM, Li YF, Tang DY, Su KM, Yan XC, Li GY, Zheng DS, Li LH, Liu X (2011) Investigation of horticultural crop resources in Yongde County, Yunnan Province. Journal of Plant Genetic Resources, 12, 413-418. (in Chinese with English abstract) [陈洪明, 李亚非, 唐德英, 苏开美, 严兴 初, 李国钰, 郑殿升, 李立会, 刘旭 (2011) 云南永德县 民族聚居区园艺作物种质资源调查. 植物遗传资源学报,
12, 413-418.]

Khasbagan, Ye RH, Zhao H (2011) Study on traditional knowledge of wild edible plants used by the Mongolians in Xilingol typical steppe area. Plant Diversity and Resources, 33, 239-246. (in Chinese with English abstract) [哈斯巴根, 晔薷罕, 赵晖 (2011) 锡林郭勒典型草原地区蒙古族野 生食用植物传统知识研究. 植物分类与资源学报, 33, 239-246.]

Li WF, Lin LF, Qin R, Liu FW (2010) Investigation on species resources of vegetable culture in ethnic groups. Southwest China Journal of Agricultural Sciences, 23, 976-980. (in Chinese with English abstract) [李卫芬, 林立飞, 秦荣, 刘 发万 (2010) 云南民族特用蔬菜资源文化调查. 西南农 业学报, 23, 976-980.]

Li WF, Gao AN, Li JQ, Lu YY, Zheng DS, Li LH, Liu X, Jiang M (2016) Preliminary investigation on ethnic traditional knowledge of vegetable resources in Guizhou. Journal of Plant Genetic Resources, 17, 786-790. (in Chinese with English abstract) [李卫芬, 高爱农, 李金强, 卢颖颖, 郑殿 升, 李立会, 刘旭, 江明 (2016) 贵州蔬菜资源的民族传 统文化初步调查. 植物遗传资源学报, 17, 786-790.]

Liu CY, Du F, Wang J, Guo SP, Xi ZP, Leng TX (2012) Ethnobotanical survey of wild food plants used by Wa people in Cangyuan County of Yunnan Province. Journal of West China Forestry Science, 41(5), 42-49. (in Chinese with English abstract) [刘川宇, 杜凡, 汪健, 郭淑萍, 席赠兴, 冷 天金金 (2012) 仾族野生食用植物资源的民族植物学研究. 西部林业科学, 41(5), 42-49.]

Liu YT, Long CL (2001) Cultural dimension in edible flowers among ethnic groups in Yunnan. Chinese Journal of Nature, 23，292-297+246-310. (in Chinese) [刘怡涛, 龙春林 (2001) 云南各民族食用花卉中的人文因素. 自然杂志, 23, 292-297+246-310.]

Long CL, Zhang FY, Pei SJ, Chen SY (1999) Impacts of traditional culture of Yi Nationality upon biodiversity in Zixishan Mountain area, Yunnan. Chinese Biodiversity, 7, 245-249. (in Chinese with English abstract) [龙春林, 张方 玉, 裴盛基, 陈三阳 (1999) 云南紫溪山彝族传统文化对 生物多样性的影响. 生物多样性, 7, 245-249.]

Long L (2005) On the homologous culture of medicine and food of the Wa Nationality. Journal of Yunnan Nationalities University (Social Sciences), 22(5), 100-102. (in Chinese with English abstract) [龙鳞 (2005) 恆族的药食同源文化. 云南民族大学学报(哲学社会科学版), 22(5), 100-102.]

Luo ZJ (1995) The Social History and Culture of Wa People. China Minzu University Press, Beijing. (in Chinese) [罗之 基 (1995) 㑑族社会历史与文化. 中央民族大学出版社, 北京.]

Pei SJ (2011) Traditional culture and biodiversity conservation. Bulletin of Chinese Academy of Sciences, 26, 190-196. (in Chinese with English abstract) [裴盛基 (2011) 民族文化 与生物多样性保护. 中国科学院院刊, 26, 190-196.]

Pieroni A, Nedelcheva A, Dogan Y (2015) Local knowledge of 
medicinal plants and wild food plants among Tatars and Romanians in Dobruja (south-east Romania). Genetic Resources \& Crop Evolution, 62(4), 1-16.

Su Y, Yang ZY, Cao YS, Liu YF, Chen XY, Kui LM, Liu XL (2012) Characteristics and geographical distribution of Yunnan crop resources. XVI. Distribution diversity of vegetable germplasm in stress resistance. Journal of Plant Genetic Resources, 13, 52-56. (in Chinese with English abstract) [苏艳, 杨忠义, 曹永生, 刘义富, 陈晓艳, 奎丽梅, 刘晓利 (2012) 云南作物资源特征特性及生态地理分布 研究. XVI. 蔬菜资源的多样性分布研究. 植物遗传资源 学报, 13, 52-56.]

Tamang B, Tamang JP (2014) Traditional knowledge of biopreservation of perishable vegetable and bamboo shoots in northeast India as food resources. Indian Journal of Traditional Knowledge, 8(8), 89-95.

Wang JR, Long CL (1995) Ethnobotanical study of traditional edible plants of Ji Nuo Nationality. Plant Diversity and Resources, 17, 161-168. (in Chinese with English abstract) [王 洁如, 龙春林 (1995) 基诺族传统食用植物的民族植物 学研究. 植物分类与资源学报, 17, 161-168.]

Wang YJ, Wang YL, Jiao AX, Caiji ZM, Yang JB, Ruan RC, Xue DY (2015) Influence of national traditional culture on crop genetic diversity - take an example of Kam Sweet Rice in Liping County of Guizhou Province. Journal of Natural Resources, 30, 617-628. (in Chinese with English abstract) [王艳杰, 王艳丽, 焦爱霞, 才吉卓玛, 杨京彪, 阮仁超, 薛达元 (2015) 民族传统文化对农作物遗传多样性的影 响一一贵州黎平县香禾糯资源为例. 自然资源学报, 30, 617-628.]

Xu ZF, Liu HM (1995) Palm leaves Buddhism sutra culture of Xishuangbanna Dai and plant diversity conservation. Chinese Biodiversity, 3, 174-179. (in Chinese with English abstract) [许再富, 刘宏茂 (1995) 西双版纳傣族贝叶文化 与植物多样性保护. 生物多样性, 3, 174-179.]

Xu ZF (2015) Conservation of biodiversity and cultural diversity are two sides of a coin: Xishuangbanna Dai's ecological culture as an example. Biodiversity Science, 23, 126-130. (in Chinese with English abstract) [许再富 (2015) 生物多 样性保护与文化多样性保护是一枚硬币的两面: 以西双 版纳傣族生态文化为例. 生物多样性, 23, 126-130.]
Xue DY, Guo L (2009a) On concepts and protection of traditional knowledge. Biodiversity Science, 17, 135-142. (in Chinese with English abstract) [薛达元, 郭泺 (2009a) 论 传统知识的概念与保护. 生物多样性, 17, 135-142.]

Xue DY, Guo L (2009b) On protection and benefit-sharing of genetic resources and associated traditional knowledge in the ethnic areas of China. Resources Science, 31, 919-925. (in Chinese with English abstract) [薛达元, 郭泺 (2009b) 中国民族地区遗传资源及传统知识的保护与惠益分享. 资源科学, 31, 919-925.]

Xue DY, Wu JY, Zhao FW (2012) Actions, progress and prospects in implementation of the Convention on Biological Diversity during the past 20 years in China. Biodiversity Science, 20, 623-632. (in Chinese with English abstract) [薛 达元, 武建勇, 赵富伟 (2012) 中国履行《生物多样性公 约》二十年: 行动、进展与展望. 生物多样性, 20 , 623-632.]

Zheng DS, You CL, Gao AN, Li LH, Liu X (2012) Conservation and utilization on biological resources of agriculture of minority nationality in Yunnan Province and its peripheral area. Journal of Plant Genetic Resources, 13, 699-703. (in Chinese with English abstract) [郑殿升, 游承俐, 高爱农, 李立会, 刘旭 (2012) 云南及周边地区少数民族对农业 生物资源的保护与利用. 植物遗传资源学报, 13 , 699-703.]

Zheng XL, Sun W, Li RT (2013) Ethnobotanical study on wild vegetable resources of Li Nationality. Hubei Agricultural Sciences, 52, 3856-3860. (in Chinese with English abstract) [郑希龙, 孙伟, 李榕涛 (2013) 黎族野生蔬菜资源的民 族植物学研究. 湖北农业科学, 52, 3856-3860.]

Zou H (2009) Discussion on Wa's economic and social development strategy. Journal of Sichuan College of Education, 25(10), 49-51. (in Chinese with English abstract) [邹欢 (2009) 试论仾族经济社会的发展战略. 成都师范学院学 报, 25(10), 49-51.] 